\title{
Uterine Cervix Cyst
}

National Cancer Institute

\section{Source}

National Cancer Institute. Uterine Cervix Cyst. NCI Thesaurus. Code C3977.

A cyst in the uterine cervix. 